\title{
2010 clinical practice guidelines for the diagnosis and management of osteoporosis in Canada: summary
}

\author{
Alexandra Papaioannou MD MSc, Suzanne Morin MD MSc, Angela M. Cheung MD PhD, \\ Stephanie Atkinson PhD, Jacques P. Brown MD, Sidney Feldman MD, David A. Hanley MD, \\ Anthony Hodsman MD, Sophie A. Jamal MD PhD, Stephanie M. Kaiser MD, Brent Kvern MD, \\ Kerry Siminoski MD, William D. Leslie MD MSc; for the Scientific Advisory Council of \\ Osteoporosis Canada
}

Previously published at www.cmaj.ca

$\mathrm{S}$ ince the publication of the Osteoporosis Canada guidelines in 2002, there has been a paradigm shift in the prevention and treatment of osteoporosis and fractures. ${ }^{1,2}$ The focus now is on preventing fragility fractures and their negative consequences, rather than on treating low bone mineral density, which is viewed as only one of several risk factors for fracture. Given that certain clinical factors increase the risk of fracture independent of bone mineral density, it is important to take an integrated approach and to base treatment decisions on the absolute risk of fracture. Current data suggest that many patients with fractures do not undergo appropriate assessment or treatment. ${ }^{3}$ To address this care gap for high-risk patients, the 2010 guidelines concentrate on the assessment and management of women and men over age 50 who are at high risk of fragility fractures and the integration of new tools for assessing the 10-year risk of fracture into overall management.

\section{Burden and care gaps}

Fragility fractures, the consequence of osteoporosis, are responsible for excess mortality, morbidity, chronic pain, admission to institutions and economic costs. ${ }^{46}$ They represent $80 \%$ of all fractures in menopausal women over age $50 .{ }^{3}$ Those with hip or vertebral fractures have substantially increased risk of death after the fracture. ${ }^{5}$ Postfracture mortality and institutionalization rates are higher for men than for women.

Despite the high prevalence of fragility fractures in the Canadian population and the knowledge that fractures predict future fractures ${ }^{8}$ fewer than $20 \%$ of women ${ }^{3.9}$ and $10 \%$ of $m e{ }^{10}$ receive therapies to prevent further fractures. These statistics contrast sharply with the situation for cardiovascular disease, where $75 \%$ of patients who have had myocardial infarction receive $\beta$-blockers to prevent another event. ${ }^{11}$

\section{Scope of the guidelines}

The target population for these guidelines is women and men over age 50 , because of the overall burden of illness in that age group. As a consequence, we focused our systematic liter-

\section{Key points}

- The management of osteoporosis should be guided by an assessment of the patient's absolute risk of osteoporosisrelated fractures.

- Fragility fracture increases the risk of further fractures and should be considered in the assessment.

- Lifestyle modification and pharmacologic therapy should be individualized to enhance adherence to the treatment plan.

ature reviews on this population. The application of these guidelines to children and young adults, as well as high-risk groups such as transplant recipients, was considered, but indepth reviews of conditions that increase risk were largely beyond the scope of these guidelines.

\section{Development of the guidelines}

The development of these guidelines followed the Appraisal of Guidelines, Research and Evaluation (AGREE) framework. ${ }^{12}$ We surveyed primary care physicians, patients, osteoporosis specialists from various disciplines, radiologists, allied health professionals and health policy-makers to identify priorities for these guidelines. We then conducted system-

From the Department of Medicine, Division of Geriatrics (Papaioannou), the Departments of Pediatrics and of Biochemistry and Biomedical Sciences, Faculty of Health Sciences (Atkinson), McMaster University, Hamilton, Ont.; the Department of Medicine (Morin), Division of General Internal Medicine, McGill University, Montréal, Que., the Department of Medicine (Cheung), the Department of Medical Imaging (Cheung), the Department of Family and Community Medicine (Feldman) and the Faculty of Medicine (Jamal), University of Toronto, Toronto, Ont.; the Department of Medicine (Brown), Université Laval, Québec, Que.; the Departments of Medicine, Community Health Sciences and Oncology (Hanley), University of Calgary, Calgary, Alta.; the Department of Medicine (Hodsman), University of Western Ontario, London, Ont.; the Division of Endocrinology and Metabolism (Kaiser), Faculty of Medicine, Dalhousie University, Halifax, NS; the Departments of Family Medicine (Kvern), Medicine (Leslie) and Radiology (Leslie), University of Manitoba, Winnipeg, Man.; and the Departments of Radiology and Medicine (Siminoski), University of Alberta, Edmonton, Alta.

CMAJ 2010. DOI:10.1503/cmaj.100771 
atic reviews of the literature according to these priorities to update our knowledge in two key areas: assessment of risk of fracture and therapies for osteoporosis. Additional topics covered here were identified as important for the management of osteoporosis.

We convened a Best Practice Guidelines Committee consisting of participants from across Canada with methodologic and content expertise. We performed literature searches in seven electronic databases (Appendix 1, available at www.cmaj.ca/cgi/content/full/cmaj.100771/DC1), adapted search strategies from systematic reviews performed by the Cochrane Musculoskeletal Group and followed the PRISMA flow diagram for selection of studies, the PRESS (Peer Reviewed Electronic Search Strategy) checklist and the Cochrane Collaboration Handbook. We identified 35 papers for assessment of fracture risk, published from January 1990 to December 2009. We used the systematic review of osteoporosis therapies of MacLean and colleagues ${ }^{13}$ who included 76 randomized trials and 24 meta-analyses, supplemented with data from 30 randomized controlled trials published since 2008. We abstracted all papers, graded them for quality of evidence and assigned a level of evidence using established criteria (Appendix 1, available at www.cmaj.ca/cgi/content /full/cmaj.100771/DC1). ${ }^{1}$ We then developed and graded initial recommendations. We incorporated relevant data up to Sept. 19, 2010.

An expert panel, consisting of members of the Osteoporosis Canada Scientific Advisory Council, members of stakeholder organizations, family physicians and experts from across Canada, met to discuss the initial recommendations. The group used a modified RAND/University of California, Los Angeles Delphi method for developing consensus to ensure clinical relevance and applicability. ${ }^{14}$ The Guidelines Committee and the Executive Committee of the Osteoporosis Canada Scientific Advisory Council then reviewed the rec- ommendations. The revised recommendations (presented below with grades in square brackets) are based on the feedback provided and were endorsed by the expert panel.

\section{Clinical recommendations}

\section{Who should I assess for osteoporosis and fracture risk?}

Women and men over age 50 should be assessed for risk factors for osteoporosis and fracture to identify those at high risk for fractures.

1. Individuals over age 50 who have experienced a fragility fracture should be assessed [grade A].

\section{How do I assess for osteoporosis and fracture risk?}

A detailed history and a focused physical examination are recommended to identify risk factors for low bone mineral density, falls and fractures, as well as undiagnosed vertebral fractures (Appendix 1, available at www.cmaj.ca/cgi/content /full/cmaj.100771/DC1). In selected individuals, bone mineral density should be measured with dual-energy x-ray absorptiometry (Table 1).

1. Measure height annually, and assess for the presence of vertebral fractures [grade $\mathrm{A}$ ].

2. Assess history of falls in the past year. If there has been such a fall, a multifactorial risk assessment should be conducted, including the ability to get out of a chair without using arms [grade $\mathrm{A}$ ].

\section{What investigations should I order initially?}

For most patients with osteoporosis, defined as bone mineral density of 2.5 or more standard deviations below the peak bone mass for young adults (i.e., T-score $\leq-2.5$ ), only limited laboratory investigations are usually required (Box 1). Increased values for bone turnover markers are associated with an approximately two-fold increased risk of fractures,

Table 1: Indications for measuring bone mineral density

Older adults (age $\geq 50 \mathrm{yr}$ )

Younger adults (age $<50 \mathrm{yr}$ )

Age $\geq 65$ yr (both women and men)

Clinical risk factors for fracture (menopausal women, men age 50-64 yr)

Fragility fracture after age $40 \mathrm{yr}$

Prolonged use of glucocorticoids*

Use of other high-risk medicationst

Parental hip fracture

Vertebral fracture or osteopenia identified on radiography

Current smoking

High alcohol intake

Low body weight $(<60 \mathrm{~kg}$ ) or major weight loss $(>10 \%$ of body weight at age $25 \mathrm{yr}$ )

Rheumatoid arthritis

Other disorders strongly associated with osteoporosis
Fragility fracture

Prolonged use of glucocorticoids*

Use of other high-risk medicationst

Hypogonadism or premature menopause (age $<45 \mathrm{yr}$ )

Malabsorption syndrome

Primary hyperparathyroidism

Other disorders strongly associated with rapid bone loss and/or fracture

*At least three months cumulative therapy in the previous year at a prednisone-equivalent dose $\geq 7.5 \mathrm{mg}$ daily.

tFor example, aromatase inhibitors or androgen deprivation therapy. 
Box 1: Recommended biochemical tests for patients being assessed for osteoporosis

- Calcium, corrected for albumin

- Complete blood count

- Creatinine

- Alkaline phosphatase

- Thyroid-stimulating hormone

- Serum protein electrophoresis (for patients with vertebral fractures)

- 25-Hydroxyvitamin D*

* Should be measured after three to four months of adequate supplementation and should not be repeated if an optimal level (at least $75 \mathrm{nmol} / \mathrm{L}$ ) is achieved.

which is largely independent of bone mineral density; however the value of measuring these markers to estimate an individual's risk of fracture is unclear. ${ }^{15}$

1. Perform additional biochemical testing to rule out secondary causes of osteoporosis in selected patients, on the basis of the clinical assessment [grade D].

2. Measure serum level of 25-hydroxyvitamin D in individuals who will receive pharmacologic therapy for osteoporosis, those who have sustained recurrent fractures or have bone loss despite osteoporosis treatment, and those with comorbid conditions that affect absorption or action of vitamin D [grade D].

3. Serum 25-hydroxyvitamin $\mathrm{D}$ should be measured after three to four months of adequate supplementation and should not be repeated if an optimal level ( $\geq 75 \mathrm{nmol} / \mathrm{L})$ is achieved [grade B].

4. Serum 25-hydroxyvitamin D should not be measured in healthy adults at low risk of vitamin D deficiency, i.e., without osteoporosis or conditions affecting the absorption or action of vitamin D [grade D].

Assessment for vertebral fractures by dual-energy $\mathrm{x}$-ray absorptiometry is available as an option on some bone densitometers. ${ }^{16}$ Vertebral fractures unrelated to trauma are best defined (on lateral radiographs or via vertebral fracture assessment) as vertebral height loss of $25 \%$ or more with disruption of the end plate. Such fractures are associated with a five-fold increase in the risk of future vertebral fractures relative to those without vertebral fractures. ${ }^{17}$

1. Perform lateral thoracic and lumbar spine radiography or vertebral fracture assessment by dual-energy x-ray absorptiometry if clinical evidence is suggestive of a vertebral fracture [grade A].

\section{How do I assess 10-year fracture risk?}

Currently, two closely related tools are available in Canada for estimating the 10-year risk of a major osteoporotic fracture (i.e., fracture of the hip, vertebra [clinical], forearm or proximal humerus): the updated tool of the Canadian Association of Radiologists and Osteoporosis Canada (CAROC; see Www.osteoporosis.ca ${ }^{18}$ and the Fracture Risk Assessment tool (FRAX) of the World Health Organization (WHO), specific for Canada (www.sheffield.ac.uk/FRAX/tool.jsp? country=19). ${ }^{19}$ Both use the bone mineral density or T-score for the femoral neck only. They have been calibrated using the same Canadian fracture data and have been directly validated in Canadians..$^{20-22}$ The 2010 version of the Canadian Association of Radiologists and Osteoporosis Canada tool replaces the 2005 version, which used Swedish fracture data. ${ }^{23}$

The Canadian Association of Radiologists and Osteoporosis Canada tool stratifies women and men over age 50 into three zones of risk for major osteoporotic fracture within 10 years (Figure 1): ${ }^{23}$ low $(<10 \%)$, moderate $(10 \%-20 \%)$ and high (> 20\%). An initial risk category is obtained from age, sex and $\mathrm{T}$-score for the femoral neck, derived from the reference range for white women of the National Health and Nutrition Examination Survey III. ${ }^{18}$ Certain clinical factors increase the risk of fracture independent of bone mineral density, the most important being the presence of a prior fragility fracture after age $40^{8}$ and recent prolonged use of systemic glucocorticoids (i.e., at least three months cumulative use during the preceding year at a prednisone-equivalent dose $\geq 7.5 \mathrm{mg}$ daily). ${ }^{24}$ The presence of either risk factor raises the individual's risk to the next risk category (i.e., from low to moderate or from moderate to high). When both are present, the patient is considered to have a high risk of fracture, regardless of bone mineral density. ${ }^{18}$

The WHO Fracture Risk Assessment tool uses sex, age, body mass index, prior fracture, parental hip fracture, prolonged glucocorticoid use, rheumatoid arthritis (or secondary causes of osteoporosis), current smoking, alcohol intake (three or more units daily) and (optionally) bone mineral density of the femoral neck. Fracture discrimination using the WHO Fracture Risk Assessment tool with bone mineral density is better than the Fracture Risk Assessment tool without bone mineral density or bone mineral density alone. ${ }^{25}$ Bone mineral density of the lumbar spine is not considered in the initial risk assessment for either of these two tools, and fracture risk is slightly underestimated when the lumbar spine T-score is much lower than the hip T-score. ${ }^{26}$

Observed fracture rates for women and men are in close agreement to the rates predicted by both of these tools. ${ }^{18}$ The WHO Fracture Risk Assessment tool is based upon a more complete set of clinical risk factors and can be used even without results for bone mineral density, but the calculations require access to the system's software, website or paper charts. The 2010 version of the Canadian Association of Radiologists and Osteoporosis Canada tool is less complete but is easier to use. There is high concordance between the two systems (about $90 \%$ ) in risk categorization. ${ }^{18}$ Differences, when they occur, usually relate to the presence of one or more risk factors that contribute to the Canadian version of the WHO Fracture Risk Assessment tool but that are not considered in the 2010 version of the Canadian Association of Radiologists and Osteoporosis Canada tool (parental history of hip fracture, smoking, excess alcohol intake, rheumatoid arthritis). The choice of tool is largely a matter of personal preference and convenience.

Neither of these models should be applied to individuals younger than age 50 . For individuals younger than age 50 with medical conditions that may have adverse skeletal consequences, risk assessment and treatment considerations are complex and often benefit from consultation with a specialist. In addition, the results obtained with these risk assessment tools 


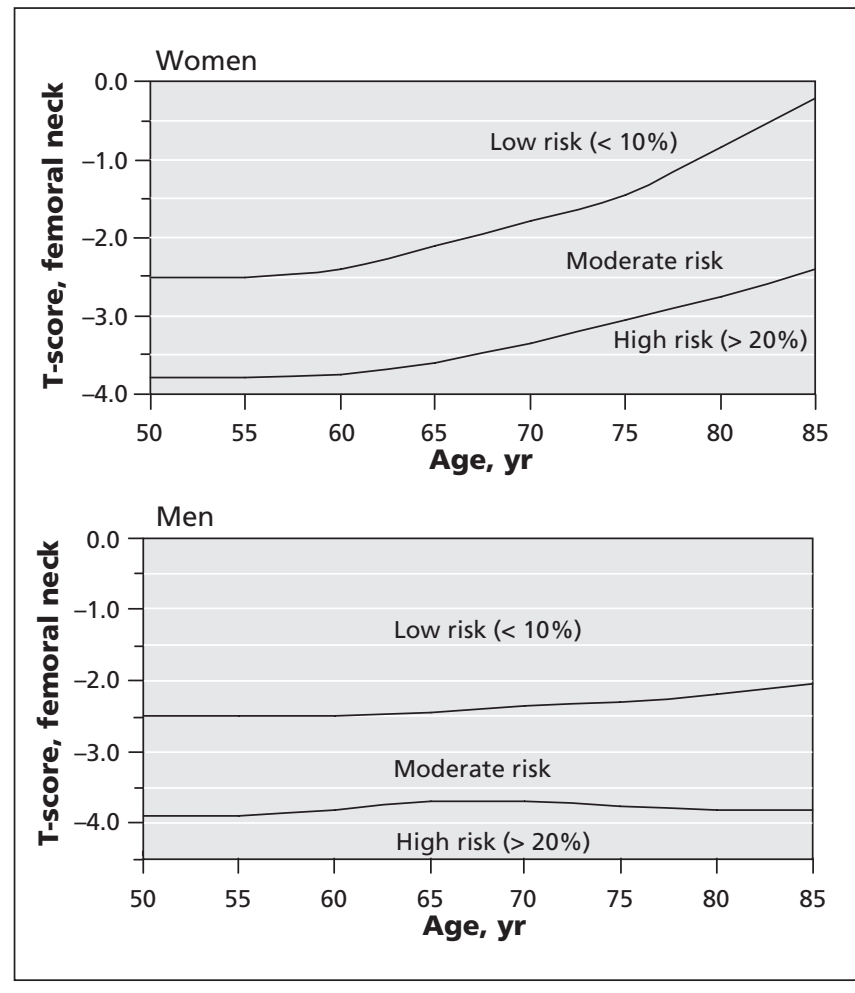

Figure 1: Assessment of basal 10-year risk of fracture with the 2010 tool of the Canadian Association of Radiologists and Osteoporosis Canada. The T-score for the femoral neck should be derived from the National Health and Nutrition Education Survey III reference database for white women. Fragility fracture after age 40 or recent prolonged use of systemic glucocorticoids increases the basal risk by one category (i.e., from low to moderate or moderate to high). This model reflects the theoretical risk for a hypothetical patient who is treatmentnaive; it cannot be used to determine risk reduction associated with therapy. Individuals with a fragility fracture of a vertebra or hip and those with more than one fragility fracture are at high risk of an additional fracture.

reflect the theoretical risk of a patient who is treatment-naive; they do not reflect any reduction in risk associated with therapy.

The software for the Canadian version of the WHO Fracture Risk Assessment tool is not yet widely available on bone mineral density machines; therefore, for purposes of reporting bone mineral density, the 2010 version of the Canadian Association of Radiologists and Osteoporosis Canada tool is the only system that can be applied on a national basis at the pres ent time. This situation may change as the WHO Fracture Risk Assessment software becomes more widely available. Clinical practitioners need to be aware of the WHO Fracture Risk Assessment tool, given its international importance as the 10year risk assessment system developed and recommended by the WHO and given that many patients will have access to the tool's website. Some clinical practitioners may also prefer the versatility of the WHO Fracture Risk Assessment tool, which allows assessment of risk in the absence of a bone mineral density measurement and is more accurate for patients with one or more of the additional risk factors listed above.

1. Assessment of the absolute risk of fracture should be based on established factors, including age, bone mineral density, prior fragility fractures and glucocorticoid use [grade A].

2. The 2010 version of the Canadian Association of Radiologists and Osteoporosis Canada tool and the Canadian version of the WHO Fracture Risk Assessment tool should be used in Canada, because they have been validated in the Canadian population [grade A].

3. For purposes of reporting bone mineral density, the 2010 version of the Canadian Association of Radiologists and Osteoporosis Canada tool is currently the preferred national risk assessment system [grade D].

4. Only the T-score for the femoral neck (derived from the reference range for white women of the National Health and Nutrition Education Survey III) should be used to calculate risk of future osteoporotic fractures under either system [grade D].

5. Individuals with a T-score for the lumbar spine or total hip $\leq-2.5$ should be considered to have at least moderate risk [grade D].

6. Multiple fractures confer greater risk than a single fracture. In addition, prior fractures of the hip and vertebra carry greater risk than fractures at other sites [grade B].

\section{What are the therapeutic options?}

\section{Exercise and prevention of falls}

Exercise improves quality of life for those with osteoporosis, particularly in the domains of physical function and pain, and improves muscle strength and balance. ${ }^{27}$ Although there is limited evidence that exercise programs reduce fractures, one study showed that a program of moderate to vigorous walking reduced the risk of hip fractures. ${ }^{28}$ Home safety assessment was effective only for those with severe visual impairment and others at high risk for falls. ${ }^{29}$ Removal of an individual's first cataract reduced the frequency of falls, ${ }^{29}$ but interventions to reduce falls did not reduce fractures. ${ }^{30}$ Hip protectors have been cost-effective in reducing hip fractures among residents of Canadian long-term care facilities but not for those residing in the community, probably because of poor compliance. ${ }^{31}$

1. Exercises involving resistance training appropriate for the individual's age and functional capacity and/or weightbearing aerobic exercises are recommended for those with osteoporosis or at risk for osteoporosis [grade B].

2. Exercises to enhance core stability and thus to compensate for weakness or postural abnormalities are recommended for individuals who have had vertebral fractures [grade B].

3. Exercises that focus on balance, such as tai chi, or on balance and gait training should be considered for those at risk of falls [grade $\mathrm{A}$ ].

4. Use of hip protectors should be considered for older adults residing in long-term care facilities who are at high risk for fracture [grade B].

\section{Calcium and vitamin D}

There is controversy about both the efficacy of calcium supplementation for reducing fractures ${ }^{32,33}$ and the potential adverse effects of high-dose supplementation. ${ }^{34}$ Another group within Osteoporosis Canada (of which some of the cur- 
rent authors were members) recently developed guidelines on vitamin D. ${ }^{35}$ Here, we highlight the major changes in vitamin D recommendations from the 2002 guidelines of Osteoporosis Canada.

1. The total daily intake of elemental calcium (through diet and supplements) for individuals over age 50 should be $1200 \mathrm{mg}$ [grade B].

2. For healthy adults at low risk of vitamin D deficiency, routine supplementation with 400-1000 IU (10-25 $\mu \mathrm{g})$ vitamin $\mathrm{D}_{3}$ daily is recommended [grade $\mathrm{D}$ ].

3. For adults over age 50 at moderate risk of vitamin D deficiency, supplementation with 800-1000 IU (20-25 $\mu \mathrm{g}$ ) vitamin $\mathrm{D}_{3}$ daily is recommended. To achieve optimal vitamin D status, daily supplementation with more than 1000 IU $(25 \mu \mathrm{g})$ may be required. Daily doses up to $2000 \mathrm{IU}$ (50 $\mu \mathrm{g})$ are safe and do not necessitate monitoring [grade $\mathrm{C}$ ].

4. For individuals receiving pharmacologic therapy for osteoporosis, measurement of serum 25-hydroxyvitamin D should follow three to four months of adequate supplementation and should not be repeated if an optimal level $(\geq 75 \mathrm{nmol} / \mathrm{L})$ is achieved [grade D].

\section{Pharmacologic therapy}

A growing number of therapeutic options are available in Canada, both antiresorptive agents (bisphosphonates, receptor activator for nuclear factor $\kappa \mathrm{B}$ [RANK] ligand inhibitor, selective estrogen receptor modulator, hormone therapy, calcitonin) and a bone-forming agent (teriparatide), with a range of dosing frequencies and routes of administration. There is consistent evidence from randomized clinical trials that all therapies currently available in Canada reduce the risk of vertebral fractures for menopausal women with osteoporosis (as defined by a T-score $\leq-2.5){ }^{13}$ There is also evidence that some interventions prevent nonvertebral and/or hip fractures ${ }^{36}$ and may reduce the mortality rate among individuals at high risk for fractures ${ }^{37,38}$ (Appendix 1, available at www.cmaj.ca /cgi/content/full/cmaj.100771/DC1). Women with prior fragility fractures affecting the vertebra or hip also benefit from pharmacologic intervention. In general, pharmacotherapy reduces the risk of vertebral fracture by $30 \%$ to $70 \%$, depending on the agent and level of adherence. The effect on nonvertebral fractures is lower and varies by fracture site. There is inconsistent evidence regarding the benefits of pharmacologic therapy for those who have sustained a fracture at a site other than the hip or the spine (e.g., the wrist), unless they also have an osteoporotic T-score. Both calcitonin and teriparatide may decrease the pain associated with vertebral fractures..$^{39,40}$

Few studies of men have assessed the reduction of fracture rate as a primary outcome. ${ }^{13}$ Systematic reviews and metaanalyses have found reductions in vertebral fractures with bisphosphonates, ${ }^{13,41}$ but there is no evidence that testosterone reduces fractures. ${ }^{13}$ In fact, hypogonadal and eugonadal men respond similarly to bisphosphonate therapy. ${ }^{41}$

1. For menopausal women requiring treatment of osteoporosis, alendronate, risedronate, zoledronic acid and denosumab can be used as first-line therapies for prevention of hip, nonvertebral and vertebral fractures [grade A].

2. For menopausal women requiring treatment of osteopor- osis, raloxifene can be used as a first-line therapy for prevention of vertebral fractures [grade A].

3. For menopausal women requiring treatment of osteoporosis in combination with treatment for vasomotor symptoms, hormone therapy can be used as first-line therapy for prevention of hip, nonvertebral and vertebral fractures [grade A].

4. For menopausal women intolerant of first-line therapies, calcitonin or etidronate can be considered for prevention of vertebral fractures [grade B].

5. For men requiring treatment of osteoporosis, alendronate, risedronate and zoledronic acid can be used as first-line therapies for prevention of fractures [grade D].

6. Testosterone is not recommended for the treatment of osteoporosis in men [grade B].

\section{Adverse effects}

In this section, we highlight issues that are common or that have surfaced in postmarketing surveillance. Some of these issues remain unresolved.

High-dose calcium supplementation may increase the risk of renal calculi and cardiovascular events. ${ }^{33,34}$ Bisphosphonates may cause self-limited flu-like symptoms, especially after the first dose of zoledronic acid by infusion (reported in up to $10 \%$ of patients). ${ }^{42}$ Denosumab may increase the risk of cellulitis. ${ }^{43}$ Raloxifene and hormone therapy increase the risk of thromboembolic events, including pulmonary embolism. ${ }^{13}$ Teriparatide can cause hypercalciuria and hypercalcemia, both generally mild and both resolving spontaneously or with discontinuation of calcium supplementation. ${ }^{13}$

Whether bisphosphonate therapy for osteoporosis increases the risk of osteonecrosis of the jaw, atypical fractures of the femur, esophageal cancer or atrial fibrillation remains controversial. Osteonecrosis of the jaw is defined as an area of exposed alveolar bone in the mandible or maxilla that does not heal after eight weeks. ${ }^{44}$ It is extremely rare $(<1$ case per 10000 patient-years among patients with primary osteoporosis). ${ }^{45}$ The risk is higher for those with malignancy, those undergoing radiation and chemotherapy, those receiving high-dose bisphosphonates for bone metastases or glucocorticoids, those with diabetes or poor dental hygiene, and those undergoing invasive dental procedures such as tooth extractions or implants.

Atypical fractures of the femur are those occurring in the subtrochanteric or diaphyseal regions. Although extremely rare, they may be more common among those undergoing long-term bisphosphonate therapy; however, a link has not been definitively established. Such fractures tend to appear as clean transverse or oblique "chalk-like" breaks. Some patients have prodromal thigh or groin pain. Radiographic findings may include cortical thickening with beaking. Nuclear bone scans often reveal increased uptake in the area, which suggests a stress fracture with increased remodelling. Radiography or bone scanning (or both) should be considered for individuals who have been on long-term bisphosphonate therapy and who experience new thigh pain. ${ }^{46}$

Esophageal cancer occurred in 23 patients who had been receiving bisphosphonate therapy from October 1995 to mid- 
May 2008, as described in a case series prepared by the US Food and Drug Administration; however, the number of patients not on this type of therapy who had esophageal cancer during the same period was not reported. ${ }^{47}$ Analysis of a national register found similar rates of this type of cancer in bisphosphonate-treated and untreated patients. ${ }^{48}$ Two recent large retrospective cohort studies reported conflicting results. ${ }^{49,50}$

In general, for patients at high 10-year fracture risk, the benefits of pharmacologic therapy far outweigh the potential risks. These risks must be placed in perspective during discussion of these issues with patients.

1. The potential benefits and risks of the prescribed agents should be discussed before therapy is initiated, to support informed decision-making [grade D].

\section{Special groups}

Bone loss associated with glucocorticoid therapy develops quickly, within three to six months, and the risk of fracture increases with doses as low as $2.5-7.5 \mathrm{mg} /$ day. ${ }^{51}$ Long-term use of glucocorticoids (three months or more) has resulted in a 30\%-50\% incidence of fractures, particularly among those over the age of 40 and those using high doses. ${ }^{13,51}$ Osteoporosis therapies, including alendronate, risedronate and teriparatide, reduce the risk of vertebral fractures and maintain bone mineral density in those taking glucocorticoids. ${ }^{13,52,53}$ Similarly, etidronate, zoledronic acid and calcitonin maintain bone mineral density in those taking glucocorticoids. ${ }^{53,54}$ For patients undergoing long-term glucocorticoid therapy, the appropriate duration of osteoporosis treatment is unknown. Bisphosphonates and denosumab maintain bone mineral density in women who are taking aromatase inhibitors and men undergoing androgen-deprivation therapy. ${ }^{55-58}$

1. For individuals over age 50 who are on long-term glucocorticoid therapy ( $\geq$ three months cumulative therapy during the preceding year at a prednisone-equivalent dose $\geq$ $7.5 \mathrm{mg}$ daily), a bisphosphonate (alendronate, risedronate, zoledronic acid) should be initiated at the outset and should be continued for at least the duration of the glucocorticoid therapy [grade A].

2. Teriparatide should be considered for those at high risk for fracture who are taking glucocorticoids ( $\geq$ three months cumulative therapy during the preceding year at a prednisone-equivalent dose $\geq 7.5 \mathrm{mg}$ daily) [grade $\mathrm{A}$ ].

3. For long-term glucocorticoid users who are intolerant of first-line therapies, calcitonin or etidronate may be considered for preventing loss of bone mineral density [grade B].

4. Women who are taking aromatase inhibitors and men who are undergoing androgen-deprivation therapy should be assessed for fracture risk, and osteoporosis therapy to prevent fractures should be considered [grade B]

\section{How should I manage patients at risk of fracture?}

An integrated approach is important for the management of patients with a risk of fracture (Figure 2). For all patients, regular weight-bearing, balance and strengthening exercises, smoking cessation, and optimization of total (dietary and supplements) calcium and vitamin D intake are recommended.
For patients at risk of falls, fall-prevention strategies should be implemented.

Within the integrated management strategy, categories of low, moderate and high fracture risk are used to guide decisions on particular therapies. The clinician should consider the ratio of benefit to harm, particularly for patients who are not at high risk. When choosing among therapies, the patient's individual risk profile, comorbid conditions, preferences and lifestyle should be considered.

1. Initiation of pharmacologic treatment for osteoporosis should be predicated on an assessment of absolute fracture risk by means of a validated fracture prediction tool [grade D].

\section{High risk}

1. Pharmacologic therapy should be offered to patients at high absolute risk (> $20 \%$ probability for major osteoporotic fracture over 10 years) [grade D].

2. Individuals over age 50 who have had a fragility fracture of the hip or vertebra and those who have had more than one fragility fracture are at high risk for future fractures, and such individuals should be offered pharmacologic therapy [grade B].

\section{Moderate risk}

Many individuals designated as being at moderate risk for fracture should be considered for pharmacologic treatment. More osteoporotic fractures occur in the moderate-risk group than the high-risk group (because there are more individuals in the moderate-risk group), even though the individual risk of fracture is higher in the high-risk group. ${ }^{18}$ Therefore, patients who are at moderate risk should undergo a careful clinical evaluation to identify additional risk factors that are not considered in the risk assessment system, and certain of these individuals should be offered pharmacologic therapy.

1. For those at moderate risk of fracture, patient preference and additional risk factors (Appendix 1, available at www.cmaj.ca/cgi/content/full/cmaj.100771/DC1) should be used to guide pharmacologic therapy [grade C].

\section{Low risk}

For patients with a low risk of fracture, pharmacologic therapy is not usually required. In general, lifestyle measures such as exercise, prevention of falls, optimization of calcium and vitamin D intake, and smoking cessation are sufficient for individuals with a low risk of fracture, provided they do not have any risk factors for rapid loss of bone mineral density.

\section{Should I monitor therapy? If so, how often?}

No randomized trials have directly assessed the value of repeat bone mineral density testing on persistence with treatment or reduction of fractures $;{ }^{59}$ however, if used correctly, serial testing can be a helpful clinical tool. ${ }^{23}$ Measurement error must be considered when interpreting serial assessments of bone mineral density to determine whether any changes are real and not simply random fluctuation or artifact. ${ }^{60}$ For patients who are undergoing treatment, repeat measurement of bone mineral density should initially be performed after one to three years; the testing interval can be increased once therapy is shown to 
Encourage basic bone health for all individuals over age 50, including regular active weight-bearing exercise, calcium (diet and supplements) $1200 \mathrm{mg}$ daily, vitamin D 800-2000 IU (20-50 $\mu \mathrm{g})$ daily and fall-prevention strategies

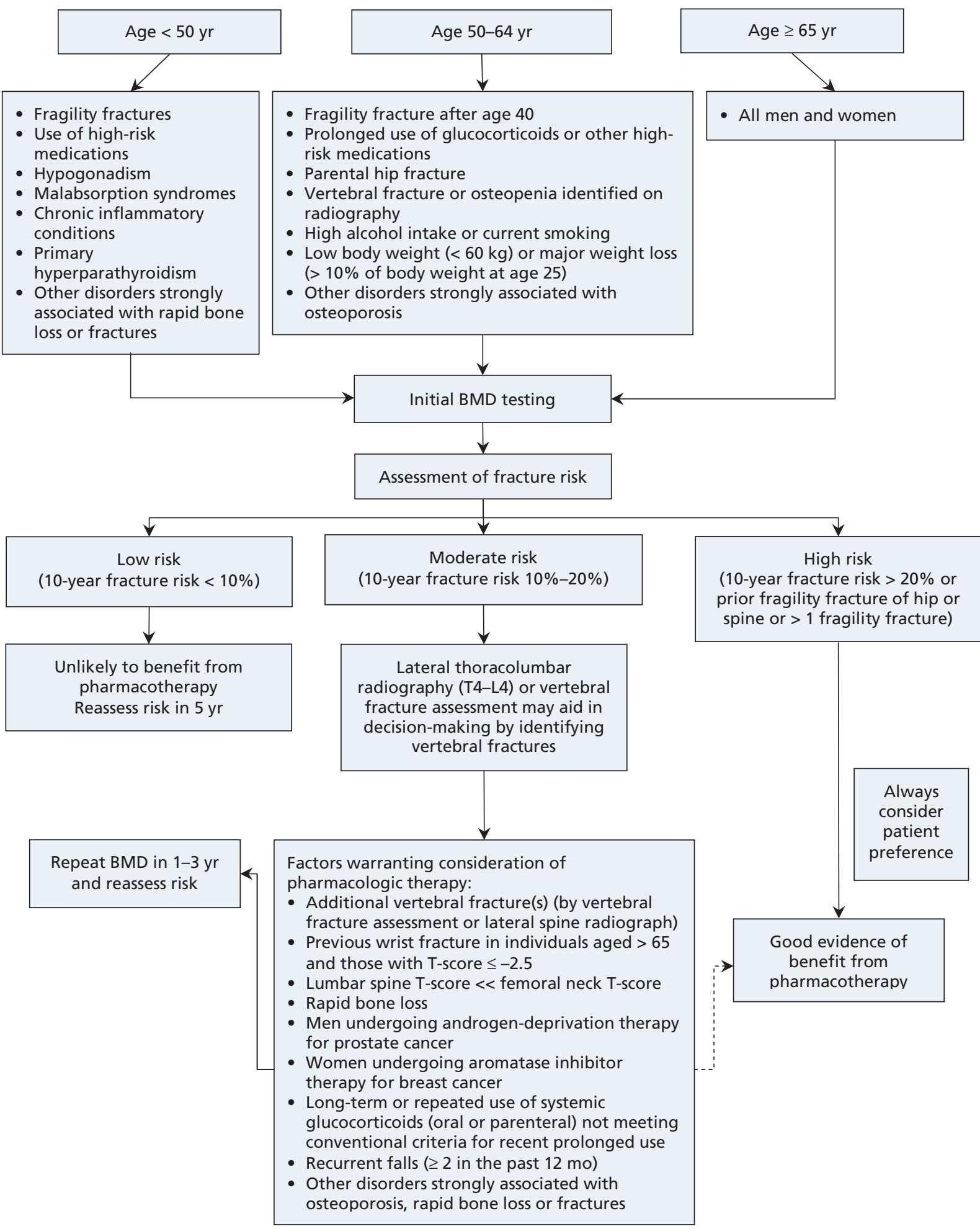

Figure 2: Integrated approach to management of patients who are at risk for fracture. BMD = bone mineral density. Dashed arrow indicates that evidence for benefit from pharmacotherapy is not as strong in this instance as for other recommendations. 
be effective. If bone mineral density has improved or remains unchanged, the patient is considered to have had a good response to therapy. Continued loss of bone mineral density or a new fracture may reflect poor adherence with therapy, failure to respond to therapy or previously unrecognized secondary causes of osteoporosis. For moderate-risk individuals, including those with a $\mathrm{T}$-score of -2.5 or below, a repeat measurement of bone mineral density should be obtained after one to three years to monitor for rapid bone loss. If bone mineral density is stable, then less frequent monitoring can be considered. For individuals with low risk of fracture and without additional risk factors for rapid loss of bone mineral density, a testing interval of 5-10 years may be sufficient. ${ }^{61}$

\section{When should I stop or use combination therapy?}

There is little evidence to support any recommendation regarding duration of therapy or the use of drug holidays. Rates of clinical vertebral fracture decreased by $55 \%$ among those who continued alendronate therapy after five years of initial treatment (for a total of 10 years) relative to those who stopped after five years, but there were no differences in rates of nonvertebral fractures or radiographic vertebral fractures. ${ }^{62}$ Discontinuation of risedronate or hormone therapy (estrogen) may result in loss of bone mineral density. ${ }^{63,64}$ Combinations of hormone therapy or raloxifene with a bisphosphonate have yielded improvement in bone mineral density, ${ }^{65,66}$ but proof of additional reduction in fracture rate is lacking.

1. Individuals at high risk for fracture should continue osteoporosis therapy without a drug holiday [grade D].

2. Clinicians should avoid simultaneously prescribing more than one antiresorptive agent for fracture reduction [grade D].

\section{When should I refer to a specialist?}

Patients with any of the following factors may benefit from referral to a physician with expertise in osteoporosis: fracture or significant ongoing loss of bone mineral density despite good adherence while on first-line therapy; intolerance of first- and second-line therapies; any secondary cause of osteoporosis that is outside the expertise of the primary care physician; and extremely low bone mineral density.

\section{Other guidelines}

Both the US National Osteoporosis Foundation and the UK National Osteoporosis Guideline Group use absolute 10-year risk of fracture to guide interventions. The National Osteoporosis Foundation recommends treating menopausal women and men over age 50 with T-score $\leq-2.5$ at the hip or spine or with a prior hip or spine fracture. In addition, patients with low bone mass (T-score between -1.0 and -2.5 ) should be treated when the 10 -year risk of hip fracture is $\geq 3 \%$ or the 10 -year risk of major osteoporosis-related fracture is $\geq 20 \% .{ }^{67}$ The National Osteoporosis Guideline Group recommends an age-dependent intervention threshold, which ranges from $7.5 \%$ risk of major osteoporotic fracture at age 50 to $30 \%$ at age $80 .^{68}$ These two approaches are different: the National Osteoporosis Foundation guidelines are driven by cost-effectiveness, whereas the National Osteoporosis Guideline Group uses a translational approach to determine treatment thresholds. A much smaller proportion of the population would be treated under the approach of the National Osteoporosis Guideline Group than that of the National Osteoporosis Foundation. It is unclear which approach is better suited to the Canadian context.

\section{Knowledge translation}

Knowledge translation for these guidelines was developed through the knowledge-to-action framework. A systematic review has shown that disease management tools for osteoporosis that targeted both the physician and patient and that were multifaceted (such as having reminders, education and risk assessment tools in either paper or electronic format) improved appropriate use of both bone mineral density testing and treatment. ${ }^{69}$ Several Canadian randomized controlled trials have demonstrated the effectiveness and cost-effectiveness of multifaceted approaches in which case managers coordinate care..$^{70,71}$ Therefore, we developed a toolkit and a dissemination strategy after widespread national consultation with primary care physicians, patients, allied health professionals, specialists, radiologists and health policy-makers. A group of Canadian knowledge translation and osteoporosis specialists has been convened to develop and evaluate novel tools that will enhance the implementation of these guidelines. In addition, more than 10 professional organizations have endorsed these guidelines and will assist in its dissemination (Appendix 1, available at www.cmaj.ca/cgi/content/full/cmaj.100771/DC1). Tools and resources can be found at www.osteoporosis.ca.

1. Following a fragility fracture, an educational initiative should be targeted at both the patient and the primary care physician [grade B].

2. Case management is recommended as an effective approach to postfracture care, to improve both the diagnosis and the management of osteoporosis [grade A].

3. Point-of-care tools and other targeted strategies are recommended to support the implementation of osteoporosis guidelines in clinical practice [grade B].

\section{Directions for future research}

Many gaps exist in our current knowledge about how to best prevent fractures and their negative consequences. Future research should examine the risk of fractures in special populations (including younger patients who have already had a frature and younger patients who are taking glucocorticoids), the value of bone turnover markers in assessing individuals' fracture risk and monitoring their treatment, whether exercise or fall-prevention programs reduce fractures and the optimal daily dose of vitamin D for musculoskeletal and other health benefits.

This article was peer reviewed.

Competing interests: All authors received consulting fees and travel support from Osteoporosis Canada during the preparation of this article. In addition, Alexandra Papaioannou has been an advisory board member for Amgen, Eli Lilly, Merck Frosst, Novartis and Procter \& Gamble; has served as a consultant to Amgen, Aventis Pharma, Eli Lilly, Lundbeck Canada Inc., Merck Frosst, Novartis, Procter \& Gamble, Servier, Warner Chillcott and Wyeth- 
Ayerst; has received unrestricted research grants from Amgen, Eli Lilly, Merck Frosst, Procter \& Gamble and Sanofi-Aventis; has received clinical trial grants from Novartis and Pfizer; has received a research grant from the Ontario Ministry of Health and Long-Term Care; and has served as a member of the Continuing Medical Education Steering Committee of the Ontario College of Family Physicians. Suzanne Morin has been an advisory board member for Amgen, Eli Lilly, Novartis and Warner-Chilcott and has received speaker's honoraria from Amgen, Novartis and Merck. Angela M. Cheung has been an advisory board member for Amgen and Eli Lilly; has served as a consultant for Merck; and has received speaker's honoraria from Amgen, Eli Lilly, Merck, Novartis and Warner Chilcott. Stephanie Atkinson has served as a consultant to Pfizer and Wyeth Nutritionals and has participated in a multisite clinical trial funded by Novartis. Jacques P. Brown has been an advisory board member for Amgen, Eli Lilly, Merck, Novartis and Warner Chilcott; has served as a consultant for Amgen, Eli Lilly, Merck, Novartis and Warner Chilcott; has received grants from Abbott, Amgen, Eli Lilly, GlaxoSmithKline, Merck, Novartis, Pfizer, Roche, Sanofi-Aventis, Servier and Warner Chilcott; and has received speaker's honoraria from Amgen, Eli Lilly, Merck, Novartis and Warner Chilcott. David A. Hanley has served as an advisory board member for Amgen Canada, Eli Lilly Canada, Novartis Canada, NPS Pharmaceuticals, Servier Canada and Warner Chilcott; has participated in clinical trials funded by Amgen, Eli Lilly, Novartis, NPS Pharmaceuticals, Pfizer, Servier and Wyeth Ayerst; and has received speaker's honoraria from Amgen Canada, Eli Lilly Canada, Novartis Canada, NPS Pharmaceuticals and Servier Canada. Anthony Hodsman has been an advisory board member for Amgen Canada, Novartis Canada, Procter \& Gamble Canada, Shire Pharmaceuticals Canada and Warner-Chilcott Canada; has served as a consultant to Cytochroma Canada; and has received speaker's honoraria from McGill University and Novartis Canada. Stephanie M. Kaiser has served as an advisory board member for Amgen, AstaZeneca, Bristol Myers Squibb, Eli Lilly Canada, Merck Frosst/Schering, Novartis and Servier; has received speaker's honoraria from Amgen, AstraZeneca, Eli Lilly, Merck Frosst/Schering Plough, Novartis, Procter and Gamble (now Warner Chilcott/Aventis), and Servier Canada; has received payment for development of educational presentations from Eli Lilly Canada Inc.; and has received travel funds for activities unrelated to this paper from Amgen Canada. Brent Kvern has been an advisory board member for the Alliance for Better Bone Health (sponsored by SanofiAventis and Warner) and for Amgen Canada; has served as a consultant for Servier Canada; has received honoraria from the Alliance for Better Bone Health, Amgen Canada, Eli Lilly, Merck Frosst Canada and Servier Canada; and has received payment for development of educational presentations from the Alliance for Better Bone Health, Amgen Canada, Eli Lilly, Merck Frosst Canada and Servier Canada. William D. Leslie has been an advisory board member for Amgen, Genzyme and Novartis; has received unrestricted research grants from Amgen, Genzyme, Merck Frosst, Procter \& Gamble and Sanofi-Aventis; has received speaker's fees from Amgen and Merck Frosst; and has received travel funds for activities unrelated to this paper from Genzyme. No additional competing interests declared for Sidney Feldman, Sophie Jamal and Kerry Siminoski.

Contributors: The Clinical Practice Guidelines for the Diagnosis and Management of Osteoporosis in Canada were created with input from more than 30 experts and stakeholders in the field of osteoporosis. Dr. Papaioannou, chair of the Therapies Working Group, and Dr. Leslie, chair of the Risk Assessment Working Group, were the overall project leaders. The members of the two working groups (Alexandra Papaioannou, Suzanne Morin, Angela M. Cheung, Stephanie Atkinson, Sophie A. Jamal, Stephanie M. Kaiser and Brent Kvern for the Therapies Working Group and William D. Leslie, Angela M. Cheung, Jacques P. Brown, Sidney Feldman, David A. Hanley, Anthony Hodsman and Kerry Siminoski for the Risk Assessment Working Group) participated in the design and development of the guidelines, including analysis and interpretation of data and writing and editing of the various sections in the full guidelines document. A smaller writing group (Alexandra Papaionnou, Suzanne Morin, Angela M. Cheung and William D. Leslie) was responsible for developing the current summary version of the guidelines, which was reviewed and approved by all members of the two working groups.

Acknowledgements: The authors thank their support team for their dedication to the guidelines project and acknowledge their contributions: Best Practices Project Coordinator Elke Henneberg of ebmed Inc. (www.ebmed.ca); researchers Loretta Hillier MA, Christina Lacchetti MHSc, Tamara Rader MLIS and Hajera Khaja MSc; and consumer representative Marg MacDonell. We also acknowledge the support of Famida Jiwa DC MHSc, Farah
Samji DC MHSc and Donna Spafford RN BA of Osteoporosis Canada. We thank the members of the expert panel for their contributions to the guidelines: Brian Lentle MD (moderator), Jacques Levesque MD, Sumit R. Majumdar MD, Heather Frame MD, Lynn Nash MD, Michel Fortier MD, Earl Bogoch MD, David Goltzman MD, Robert Josse MBBS, Colleen Metge BSc(Pharm) PhD, Louis-Georges Ste-Marie MD, Diane Theriault MD and Anne Marie Whelan PharmD. In addition, we gratefully acknowledge Gillian Hawker MD, Jonathan D. Adachi MD, Heather McDonald-Blumer MD and Irene Polidoulis MD for reviewing materials related to the manuscript.

Funding: Alexandra Papaioanou is supported by a Canadian Institutes of Health Research (CIHR)/Eli Lilly Chair in Women's Health, Angela M. Cheung by a CIHR/Institute of Gender and Health Senior Scientist Award and Sophie A. Jamal by a CIHR New Investigator Award. Osteoporosis Canada provided financial support for the face-to-face meetings and for the project coordinator and research assistants who worked under the direction of the guidelines cochairs.

\section{REFERENCES}

1. Brown JP, Josse RG; Scientific Advisory Council of the Osteoporosis Society of Canada. 2002 clinical practice guidelines for the diagnosis and management of osteoporosis in Canada. CMAJ 2002;167(10 Suppl):S1-34.

2. Cheung AM, Detsky AS. Osteoporosis and fractures: Missing the bridge? JAMA 2008;299:1468-70.

3. Bessette L, Ste-Marie LG, Jean S, et al. The care gap in diagnosis and treatment of women with a fragility fracture. Osteoporos Int 2008;19:79-86.

4. Papaioannou A, Kennedy CC, Ioannidis G, et al. The impact of incident fractures on health-related quality of life: 5 years of data from the Canadian Multicentre Osteoporosis Study. Osteoporos Int 2009;20:703-14.

5. Ioannidis G, Papaioannou A, Hopman WM, et al. Relation between fractures and mortality: results from the Canadian Multicentre Osteoporosis Study. CMAJ 2009; 181:265-71.

6. Wiktorowicz ME, Goeree R, Papaioannou A, et al. Economic implications of hip fracture: health service use, institutional care and cost in Canada. Osteoporos Int 2001; $12: 271-8$.

7. Tosteson AN, Gottlieb DJ, Radley DC, et al. Excess mortality following hip fracture: the role of underlying health status. Osteoporos Int 2007;18:1463-72.

8. Kanis JA, Johnell O, De Laet C, et al. A meta-analysis of previous fracture and subsequent fracture risk. Bone 2004;35:375-82.

9. Papaioannou A, Giangregorio L, Kvern B, et al. The osteoporosis care gap in Canada. BMC Musculoskelet Disord 2004;5:11.

10. Papaioannou A, Kennedy CC, Ioannidis G, et al. The osteoporosis care gap in men with fragility fractures: the Canadian Multicentre Osteoporosis Study. Osteoporos Int 2008;19:581-7.

11. Austin PC, Tu JV, Ko DT, et al. Factors associated with the use of evidence-based therapies after discharge among elderly patients with myocardial infarction. CMAJ 2008;179:901-8.

12. AGREE Collaboration. Development and validation of an international appraisal instrument for assessing the quality of clinical practice guidelines: the AGREE project. Qual Saf Health Care 2003;12:18-23.

13. MacLean C, Newberry S, Maglione M, et al. Systematic review: comparative effectiveness of treatments to prevent fractures in men and women with low bone density or osteoporosis. Ann Intern Med 2008;148:197-213.

14. Fitch K, Bernstein SJ, Aguilar MS, et al. The RAND/UCLA appropriateness method user's manual. Santa Monica (CA): The RAND Corporation; 2001.

15. Brown JP, Albert C, Nassar BA, et al. Bone turnover markers in the management of postmenopausal osteoporosis. Clin Biochem 2009;42:929-42.

16. Lentle BC, Brown JP, Khan A, et al. Recognizing and reporting vertebral fractures: reducing the risk of future osteoporotic fractures. Can Assoc Radiol J 2007;58:27-36.

17. Lindsay R, Silverman SL, Cooper C, et al. Risk of new vertebral fracture in the year following a fracture. JAMA 2001;285:320-3.

18. Leslie WD, Berger C, Langsetmo L, et al. Construction and validation of a simplified fracture risk assessment tool for Canadian women and men: results from the CaMos and Manitoba BMD cohorts. Osteoporos Int. In press.

19. Leslie WD, Lix LM, Langsetmo L, et al. Construction of a FRAX® model for the assessment of fracture probability in Canada and implications for treatment. Osteoporos Int. In press.

20. Leslie WD, Lix LM, Johansson H, et al.; Manitoba Bone Density Program. Independent clinical validation of a Canadian $\operatorname{FRAX}((\mathrm{R}))$ tool: fracture prediction and model calibration. J Bone Miner Res 2010 Apr 30. [Epub ahead of print].

21. Leslie WD, Tsang JF, Lix LM; Manitoba Bone Density Program. Simplified system for absolute fracture risk assessment: clinical validation in Canadian women. $J$ Bone Miner Res 2009;24:353-60.

22. Fraser L, Langsetmo L, Berger C, et al. Fracture prediction and calibration of a Canadian FRAX tool: a population-based report from CaMos. Osteoporos Int. In press.

23. Siminoski K, Leslie WD, Frame H, et al. Recommendations for bone mineral density reporting in Canada. Can Assoc Radiol J 2005;56:178-88.

24. Kanis JA, Johansson H, Oden A, et al. A meta-analysis of prior corticosteroid use and fracture risk. J Bone Miner Res 2004;19:893-9.

25. Kanis JA, Oden A, Johnell O, et al. The use of clinical risk factors enhances the performance of BMD in the prediction of hip and osteoporotic fractures in men and women. Osteoporos Int 2007;18:1033-46. 
26. Leslie WD, Lix LM, Johansson H, et al. Spine-hip discordance and fracture risk assessment: a physician-friendly FRAX enhancement. Osteoporos Int 2010. In press.

27. Li WC, Chen YC, Yang RS, et al. Effects of exercise programmes on quality of life in osteoporotic and osteopenic postmenopausal women: a systematic review and meta-analysis. Clin Rehabil 2009;23:888-96.

28. Moayyeri A. The association between physical activity and osteoporotic fractures: a review of the evidence and implications for future research. Ann Epidemiol 2008; 18:827-35.

29. Gillespie LD, Robertson MC, Gillespie WJ, et al. Interventions for preventing falls in older people living in the community. Cochrane Database Syst Rev 2009;(2):CD007146.

30. de Kam D, Smulders E, Weerdesteyn V, et al. Exercise interventions to reduce fallrelated fractures and their risk factors in individuals with low bone density: a systematic review of randomized controlled trials. Osteoporos Int 2009;20:2111-25.

31. Hip protectors in long-term care policy guidance and implementation. Ottawa $(\mathrm{ON})$ : Canadian Agency for Drugs and Technologies in Health, Health Technology Inquiry Service; 2010.

32. Tang BM, Eslick GD, Nowson C, et al. Use of calcium or calcium in combination with vitamin D supplementation to prevent fractures and bone loss in people aged 50 years and older: a meta-analysis. Lancet 2007;370:657-66.

33. Reid IR, Bolland MJ, Grey A. Effect of calcium supplementation on hip fractures Osteoporos Int 2008;19:1119-23.

34. Bolland MJ, Avenell A, Baron JA, et al. Effect of calcium supplements on risk of myocardial infarction and cardiovascular events: meta-analysis. BMJ 2010;341: c3691.

35. Hanley DA, Cranney A, Jones G, et al.; Guidelines Committee of the Scientific Advisory Council of Osteoporosis Canada. Vitamin D in adult health and disease: a review and guideline statement from Osteoporosis Canada (summary). CMAJ 2010;182:1315-9.

36. Cranney A, Guyatt G, Griffith L, et al.; Osteoporosis Methodology Group and The Osteoporosis Research Advisory Group. Meta-analyses of therapies for postmenopausal osteoporosis. IX: Summary of meta-analyses of therapies for postmenopausal osteoporosis. Endocr Rev 2002;23:570-8

37. Bolland MJ, Grey AB, Gamble GD, et al. Effect of osteoporosis treatment on mortality: a meta-analysis. J Clin Endocrinol Metab 2010;95:1174-81.

38. Lyles KW, Colon-Emeric CS, Magaziner JS, et al. Zoledronic acid and clinical fractures and mortality after hip fracture. N Engl J Med 2007;357:1799-809.

39. Knopp JA, Diner BM, Blitz M, et al. Calcitonin for treating acute pain of osteoporotic vertebral compression fractures: a systematic review of randomized, controlled trials. Osteoporos Int 2005; 16:1281-90.

40. Langdahl BL, Rajzbaum G, Jakob F, et al. Reduction in fracture rate and back pain and increased quality of life in postmenopausal women treated with teriparatide: 18-month data from the European Forsteo Observational Study (EFOS). Calcif Tissue Int 2009;85:484-93.

41. Sawka AM, Papaioannou A, Adachi JD, et al. Does alendronate reduce the risk of fracture in men? A meta-analysis incorporating prior knowledge of anti-fracture efficacy in women. BMC Musculoskelet Disord 2005;6:39.

42. Rahmani P, Morin S. Prevention of osteoporosis-related fractures among postmenopausal women and older men. CMAJ 2009;181:815-20.

43. Cummings SR, San Martin J, McClung MR, et al. Denosumab for prevention of fractures in postmenopausal women with osteoporosis. N Engl J Med 2009;361 756-65.

44. Khosla S, Burr D, Cauley J, et al. Bisphosphonate-associated osteonecrosis of the jaw: report of a task force of the American Society for Bone and Mineral Research. J Bone Miner Res 2007;22:1479-91.

45. Grbic JT, Landesberg R, Lin SQ, et al. Incidence of osteonecrosis of the jaw in women with postmenopausal osteoporosis in the health outcomes and reduced incidence with zoledronic acid once yearly pivotal fracture trial. J Am Dent Assoc 2008; 139:32-40.

46. Shane E, Burr D, Ebeling PR, et al. Atypical subtrochanteric and diaphyseal femoral fractures: report of a task force of the American Society for Bone and Mineral Research. J Bone Miner Res 2010 Sep 14. [Epub ahead of print].

47. Wysowski DK. Reports of esophageal cancer with oral bisphosphonate use. $N$ Engl J Med 2009;360:89-90.

48. Abrahamsen B, Eiken P, Eastell R. More on reports of esophageal cancer with ora bisphosphonate use. N Engl J Med 2009;360:1789; author reply 1791-2.

49. Green J, Czanner G, Reeves G, et al. Oral bisphosphonates and risk of cancer of oesophagus, stomach, and colorectum: case-control analysis within a UK primary care cohort. BMJ 2010;341:c4444.
50. Cardwell CR, Abnet CC, Cantwell MM, et al. Exposure to oral bisphosphonates and risk of esophageal cancer. JAMA 2010;304:657-63.

51. Van Staa TP, Laan RF, Barton IP, et al. Bone density threshold and other predictors of vertebral fracture in patients receiving oral glucocorticoid therapy. Arthritis Rheum 2003;48:3224-9.

52. Qaseem A, Snow V, Shekelle P, et al. Pharmacologic treatment of low bone density or osteoporosis to prevent fractures: a clinical practice guideline from the American College of Physicians. Ann Intern Med 2008;149:404-15.

53. Reid DM, Devogelaer JP, Saag K, et al. Zoledronic acid and risedronate in the prevention and treatment of glucocorticoid-induced osteoporosis (HORIZON): multicentre, double-blind, double-dummy, randomised controlled trial. Lancet 2009;373:1253-63.

54. Cranney A, Welch V, Adachi JD, et al. Calcitonin for the treatment and prevention of corticosteroid-induced osteoporosis. Cochrane Database Syst Rev 2000;(2): CD001983.

55. Tsoi D, Khan A, Nowak AK, et al. Bisphosphonates for prevention of bone loss in women with early breast cancer. Cochrane Database Syst Rev 2009;(3): CD007914.

56. Hines SL, Sloan JA, Atherton PJ, et al. Zoledronic acid for treatment of osteopenia and osteoporosis in women with primary breast cancer undergoing adjuvant aromatase inhibitor therapy. Breast 2010;19:92-6.

57. Ellis GK, Bone HG, Chlebowski R, et al. Randomized trial of denosumab in patients receiving adjuvant aromatase inhibitors for nonmetastatic breast cancer. $J$ Clin Oncol 2008;26:4875-82

58. Smith MR, Egerdie B, Hernandez Toriz N, et al. Denosumab in men receiving androgen-deprivation therapy for prostate cancer. N Engl J Med 2009;361:745-55.

59. Lewiecki EM, Watts NB. Assessing response to osteoporosis therapy. Osteoporos Int 2008; 19:1363-8.

60. Baim S, Wilson CR, Lewiecki EM, et al. Precision assessment and radiation safety for dual-energy $\mathrm{x}$-ray absorptiometry: position paper of the International Society for Clinical Densitometry. J Clin Densitom 2005;8:371-8.

61. Frost SA, Nguyen ND, Center JR, et al. Timing of repeat BMD measurements: development of an absolute risk-based prognostic model. J Bone Miner Res 2009; 24:1800-7.

62. Black DM, Schwartz AV, Ensrud KE, et al. Effects of continuing or stopping alendronate after 5 years of treatment: the Fracture Intervention Trial Long-term Extension (FLEX): a randomized trial. JAMA 2006;296:2927-38.

63. Watts NB, Chines A, Olszynski WP, et al. Fracture risk remains reduced one year after discontinuation of risedronate. Osteoporos Int 2008;19:365-72.

64. Schneider DL, Barrett-Connor EL, Morton DJ. Timing of postmenopausal estrogen for optimal bone mineral density. The Rancho Bernardo Study. JAMA 1997;277:543-7.

65. Greenspan SL, Resnick NM, Parker RA. Combination therapy with hormone replacement and alendronate for prevention of bone loss in elderly women: a randomized controlled trial. JAMA 2003;289:2525-33.

66. Johnell $\mathrm{O}$, Scheele $\mathrm{WH}, \mathrm{Lu} \mathrm{Y}$, et al. Additive effects of raloxifene and alendronate on bone density and biochemical markers of bone remodeling in postmenopausal women with osteoporosis. J Clin Endocrinol Metab 2002;87:985-92.

67. Tosteson AN, Melton LJ III, Dawson-Hughes B, et al. Cost-effective osteoporosis treatment thresholds: the United States perspective. Osteoporos Int 2008;19:437-47.

68. Kanis JA, McCloskey EV, Johansson H, et al. Case finding for the management of osteoporosis with FRAX - assessment and intervention thresholds for the UK Osteoporos Int 2008; 19:1395-408.

69. Kastner M, Straus SE. Clinical decision support tools for osteoporosis disease management: a systematic review of randomized controlled trials, J Gen Intern Med 2008;23:2095-105.

70. Majumdar SR, Beaupre LA, Harley $\mathrm{CH}$, et al. Use of a case manager to improve osteoporosis treatment after hip fracture: results of a randomized controlled trial. Arch Intern Med 2007; 167:2110-5.

71. Bogoch ER, Elliot-Gibson V, Beaton DE, et al. Effective initiation of osteoporosis diagnosis and treatment for patients with a fragility fracture in an orthopaedic environment. J Bone Joint Surg Am 2006;88:25-34.

Correspondence to: Dr. Alexandra Papaioannou, McMaster University, Hamilton Health Sciences - St. Peter's Hospital, 88 Maplewood Ave., Hamilton ON L8M 1W9; papaioannou@hhsc.ca 